\title{
EAMR
}

European Accounting and

Management Review

EUROPEAN ACCOUNTING AND MANAGEMENT REVIEW · VOL. 1, NO. 2, 85-106 MAY 2015

\section{What makes a woman to choose to work in a family company instead of a looking for a position in the work market or creating her own company?: a literature review}

\author{
Anna Akhmedova \\ Universitat Internacional de Catalunya \\ Rita Cavalloti \\ Universitat Internacional de Catalunya \\ Frederic Marimon \\ Universitat Internacional de Catalunya
}

Received March 17, 2014; accepted May 12, 2015.

\begin{abstract}
Despite seeming attractiveness to women, family firms fail to attract females to highlevel positions. Previous research was citing primogeniture, daughter invisibility and role incongruity among possible explanations. However, recent studies suggest that such "barriers to leadership" cannot statistically explain existing gap. Most of research loses sight that professionals with family business background have diverse career options and succession is only one of them. A review of literature on succession showed that men and women have slightly different understanding of extrinsic and intrinsic benefits and different valuing of transcendent motives. Furthermore, men and women perceive abilities and chances to success as a function of social experiences, which partially explains underrepresentation. In general, the literature on successors' motivation is scarce and inconclusive. This research area will gain from empirical studies - both quantitative and qualitative, using humanistic and cognitive frameworks to study career intentions of young professionals and female incumbents of family firms.
\end{abstract}

\section{KEYWORDS}

Gender, succession, family firms, career motivation. 


\section{Introduction}

Family business is one important form of business ownership that recently has become separate field of research. The interest of academics and practitioners is motivated by the role family business plays in the economy of countries and role it occupies in society. Thus, depending on definition and country the economic contribution of family business is estimated around $12-50 \%$ of national GDP and 15-60\% of workforce (i.e. Shanker, Astrahan, 1996). In European Union family businesses Family businesses account for $9 \%$ of the European Union's GDP, generate $60 \%$ of turnover of European companies and generate $40-50 \%$ of all employment (Bernard, 2013). In Spain, family businesses generate approximately $16 \%$ of GDP (26\% if calculated with affiliations) (IEF, 2009).

Family business can be both a small venture employing several family members and a big multinational corporation led by several family brunches and several generations. Despite great variability and difficulty to do qualitative research, there is a high incidence of market leaders among family businesses. Thus, according to Hermann Simon, in Europe $75 \%$ of market leading companies of middle size were family controlled (Simon, 2009). This form of enterprise has also demonstrated above-average accounting performance, profitability over the long-term, CSR, and a more sustainable practices (EFB, 2012). Furthermore, family controlled businesses showed more stable earnings per employee among business week 1000 (McConaughy, 1994, 1998).

Succession is a cornerstone issue in family business. On the one hand, the intent to pass the business to further generations is what basically differentiates family business. On the other hand, succession is also a weak point of family firm. Statistically researchers report a $30 \%$ barrier of survival of family firms after first succession and then $13 \%$ and $3 \%$ after subsequent transitions (Ward, 1987). First introduced by Ward, this statistics has been later cited and confirmed by various researches and is sometimes called a "threegeneration survival trap" (Zellweger et al., 2012).

Despite of being seemingly attractive to women - i.e. offering autonomy in choosing responsibilities, possibly higher appraisal and better remuneration, flexibility of working hours (Vadnjal and Zupan, 2007), women are underrepresented in family firms, specifically in high-level positions. From the point of view of RBV theory, family firms are losing valuable human capital. The economic loss involves not only professional skills and experience of "family business daughters", but also their social capital - networks and professional connections; emotional capital - important soft skills: "loyalty" and 
"sensitivity" to family and firm needs; and, leadership potential (Sagalnicoff, 1990), (Gillis-Donovan, 1990) (Eagly, 2003) (Sharma, 2004).

Most of the literature to date suggests that female underrepresentation in family firms is due to the fact that males are preferred over females during succession.

This stream of research reports: primogeniture (Dumas, 1989), (Hollander, 1990), daughter-invisibility (Hamilton, 2006), (Marshack, 1994), (Poza, 2001), (Fernández Pérez, 2007), (Colli, 2003) and role incongruity between a leader role, family role and gender role (Ely, 2011), (Powell, 2010), (Maleki, 2011), (Chengyan, 2013), (Eagly, 1990), (Eagly, 2003) - as factors that hold women back in the process of succession.

On the other hand, recent studies appeal less to the topic of so called "second-generation discrimination" and "barriers to leadership". For example, in recent study of Spanish companies, Pascual Garcia reports that some incidence of discriminative practices cannot statistically explain the huge gap between female and male presence in high-level positions in family firms (Pascual Garcia, 2012).

Further, some articles suggest that family business daughters are "excluding themselves" from potential successors by not showing interest (Curimbaba, 2002), (Otten-Papas, 2013) or "waiting" for some disruptive event - such as death of male successor (Wang, 2010), (Overbeke et al. 2013), (Dumas, 1989).

Apparently, the rise of individualistic trends open doors for family business sons and daughters to career options away from family business. Thus daughters might be attracted to pursue entrepreneur or external management career in case they want to be a leader. Especially an entrepreneurship might be a lucrative career option for family business daughters. First, children with family business background often chose entrepreneurship (Zellweger, 2013). Second, for women entrepreneurial career is sometimes even more attractive as it to men as it offers flexibility and meaningful work.

This makes think of supply side as an important factor contributing to female underrepresentation. However, literature on successor motivation and specifically female successor motivation or intention is scarce and lack theoretical background. Furthermore, much ink was spilled comparing entrepreneurial and external employment intents. The absence of similar interest in succession motivation is surprising given the importance of this form of business. 
To close this research gap it is proposed to conduct a review of literature. The paper is organized as follows: first, main motivation theories will be revisited and summarized. Second, literature on succession in family firms will be reviewed and a special attention will be paid to articles devoted to daughter succession. Finally, conclusions will be draught applying relevant information from succession literature on motivation frameworks. Future research directions will be proposed.

\section{Motivation theories}

Basically, motivation is what determines the action of a person. Understanding career motivation of a person provides understanding of what initiates and maintains one's decision and what may discern the person. Knowing one's motivation may help motivating others and as well improve the quality of motivation by adding important values to working curriculum.

For the purposes of this research, two types of motivation theories - humanistic and cognitive - will be revisited. Further, a brief overview of both types of theories will be provided.

\subsection{Humanistic theories}

Humanistic theories are quite intuitive - mainly because these are rooted in innate psychological needs of a human - that is anthropology of a person - providing general answer to the question of the purpose of one's life.

The starting point of discussion is the famous theory of Maslow (1970). In the historical context, Maslow and his processor Mayo (1949) - make a huge step from mechanistic and biological perspectives on motivation that were predominant at that time.

The assumption was the same as before - that a satisfied worker is more productive however, Maslow proposed a hierarchy that included not only biological and mechanistic perspectives - needs for food, physical comfort and safety, but also higher-order needs socialization, esteem and self-actualization. As esteem and self-actualization are often related to public sphere of life, the theory gave feminists grounds to argue for discrimination. On the other hand, empirical studies faced problems - i.e. needs did not appear in the form of hierarchy. 
Herzberg (1966) makes a step from an anthropologic model of Maslow to a more specific to working environment. He cuts the pyramid into two halves, suggesting higher needs motivate people, but the absence of lower needs (hygiene factors) can be a source of dissatisfaction.

McGregor (1960) draws upon the works of Maslow and Herzberg and introduces theory $\mathrm{X}$ and theory $\mathrm{Y}$ - which distinguish two types of motivation inherent to human nature: extrinsic for theory $\mathrm{X}$ (assumes that a human avoids effort and is moved by incentives that correspond to Maslow's basic needs) and intrinsic - for theory Y (assumes that human appreciate work and seeks responsibility).

Cognitive theories, that will be revisited further, initiate from the similar assumption that a human is active and seeks to act in accordance with his values, thoughts and experiences. However, these theories are taking different direction shifting attention from "content" to "process" of formation of motivation. For this and other reasons here these theories will be viewed separately.

Self-Determination Theory further expands ideas about motivational dichotomy. The theory assumes that human nature is positive: people are active, curious, inspired, striving to learn and to extend their skills. However, the theory acknowledges that individuals sometimes reject growth and responsibility. Self-Determination Theory is half content and half process. It looks at both: the innate psychological needs and conditions that foster needs for growth and responsibility.

In the content part, the theory distinguish three types of motivation: intrinsic, extrinsic and a motivation and three types of needs: needs for competence, relatedness and autonomy (Ryan and Deci, 2000). Ryan and Deci look deeper at extrinsic motivation introducing its gradation. Thus, depending on the degree of autonomy extrinsic motivation can present: "controlled behavior, introjected regulation, identified regulation and integrated regulation" (where "integrated regulation" is the type of extrinsic motivation closest to intrinsic motivation) (Ryan and Deci, 2000).

The process part of theory explains that externally controlled motivation can be internatiolized to become intrinsic (or autonomy controlled). Organismic Integration Theory (OIT) - is a sub-theory of Self-Determination Theory, which details different forms of extrinsic motivation and study factors that favor or hinder the process of 
integration of low autonomy behavior into high autonomy behavior (Ryan and Deci, 2000).

All theories discussed up to this point emphasized that acting agent is the one who benefits from his behavior. However, this does not explain why would people help each other, behave altruistically or what will hold team members together.

Answering these questions, Grant proposes prosocial motivation - desire or reason to act for the benefit of others or with intention of helping others (Grant, Berry, 2011). In the scale of prosocial motivation he cites such concepts as: "desire to help others, desire that other benefit from my work, prefer work that permit positive impact on others" (Grant, 2008). Furthermore, this type of motivation emphasizes the effort for future.

Similarly, basing in anthropology of a person, Perez Lopez proposes transcendent motivation. Accordingly, the main goal of a person lies in the interaction with others, not within the person (Lopez, 1991), (Lopez, 1996). Thus, a person should step outside his own needs in order to achieve a true happiness. Perez Lopez argues that organizational culture that does not support transcendent motives and, on the contrary, only favors individualism will have difficulties surviving in the long run. Ideally, he states, all three types of motives - extrinsic, intrinsic and transcendent; as well as all three types of needs - material, cognitive and affective - should be fulfilled in the workplace.

In sum, humanistic theories elaborate the question of general human needs - as a main driver of motivation. This way of though had come a long way in relatively short period of time. Originating from biological determinism, the theories then shifted attention to motives that belong to the acting agent - extrinsic and intrinsic; and, then, to motive of interacting with a reactive agent - transcendent. Humanistic theories are viewed universally for tasks and genders.

\subsection{Cognitive theories}

Cognitive theories assume that people are self-organizing, proactive, and self-regulating agents of their psychosocial development: they act in accordance with their values, beliefs and experience.

Most of cognitive theories are process theories - i.e. explain how the motivation is formed. These theories underline the role of culture, opinions of "important others" and experience in the formation of motivation. Due to importance of social component, 
cognitive theories provide rich ground to explain differences in gender choices. Theories coincide that differences in perception of abilities, self-esteem, and valuing of tasks - all are function of differences of social experiences.

Therefore, the strength of task-specific motivation might be different for males and females due to gender stereotypes. For example, wide-spread perception that girls are better in verbal tasks and boys in math would result that girls in general would be less motivated to study math and overcome challenges in math; and, will perform worse than they could have performed, had they been better motivated.

The first cognitive theories appeared in 60ies. The theory of White is the pioneer of this stream of thought (Harter, 1978). The theory introduced the term "effectance" - a disposition to act on the environment and a satisfaction obtained from the positive result of such action. Thus, according to first theories of achievement motivation tasks that were more difficult and challenging would be more motivating.

The expectancy-value theory of Eccles is based on the research in 1970s by Weiner and Atkinson. According to this theory people are willing to accomplish a given task in function of both: (1) whether they are expecting to succeed in the task and (2) a degree to which they value success in the task (Wigfield and Eccles, 2000). The model provides important contribution to understanding achievement motivation, domain-specific choices and corresponding gender differences.

The Theory of Planned Behavior was developed in 1970s-1980s by Ajzen and Fishbein. Initially, it was an extension of their Theory of Reasoned Action (Ajzen and Fishbein, 1980), (Fishbein and Ajzen, 1975), that needed corrections due to shortcomings of original model in dealing with behaviors over which people have incomplete volitional control.

Similarly to Expectancy-Value theory, Theory of Planned Behavior puts a lot of emphasis on the interplay of social and personal factors in shaping achievement motivation for genders.

The theory focuses on intentions - as major antecedents of behavior (Ajzen, 1991). In practice, measuring intentions is often an easy alternative to measuring achievement motivation when studying initial stages of activities. An intention to open a business, to complete highest educational degree or to dedicate oneself to a particular profession 
proved to be a relevant predictor of future action. However, as a realization of such intention may require years, it is comfortable to use intentions avoiding recall biases.

In general, Theory of Planned Behavior assumes that a person in a situation of election (career, business opportunity, etc.) would consider different possibilities in regards to opportunity costs, viability of options and plausibility of results for society (significant others) and self. The theory puts intentions to perform a behavior in the central place assuming that intentions reflect the sum of motivational factors and show how hard people are willing to work and to try (Ajzen, 1991).

Self-efficacy Theory emphasizes role of beliefs in motivation (Bandura, 1977). According to the theory people's beliefs can be changed in four ways: mastery experiences (experience in overcoming obstacles through perseverant effort), social modeling (seeing people similar to oneself succeed by sustained effort), social persuasion (one's self-beliefs can be constructed through appraisal or repeated successful activities), and physical and emotional states (reducing stress and depression through physical exercise) (Bussey and Bandura, 1999).

Similarly to Value-Expectancy Theory it widely explains gender differences in achievement motivation (basing on differences in social experiences).

In general cognitive theories are task specific and gender specific. These theories emphasize social component in formation of motivation (contrary to humanistic theories, that emphasize the role of anthropology). In general, cognitive theories suggest that gendered achievement expectations follow different trajectories. These differences seem to correlate with female underrepresentation in high-level management positions and in some professional areas. 


\section{Succession and motivation theories}

In this section a systematic review of several most important full-text collections (EBSCO, Elsevier ScienceDirect, Emerald Management Xtra, JSTOR, Sage, SCOPUS, Springer and Wiley Interscience) is conducted in order to find how career choice to become a successor in family business is explained from the point of view of motivation. Through literature review, two groups of articles are identified. First band includes articles that study succession through the lens of successors irrespectedly of gender focusing on reasons for next generation to pursue career in family firms. Second band of articles focuses specifically on corresponding experience of daughters.

\subsection{Humanistic theories and succession}

The framework that follows is built on the revisited humanistic theories of motivation. It includes three types of motivation: Extrinsic, Intrinsic and Transcendent. In line with Self-Determination Theory, four types of extrinsic motivation are distinguished: “Controlled", "Identificated", "Introjected" and "Integrated". Positive and negative perceptions are outlined.

The commitment of the next generation is crucial for the continuity of family business. Handler (1989) and Sharma (2004) have successfully drawn attention to the topic of next generation's perspective in the process of succession, and more specifically to the topic of motivation of the future leaders. Basically, if the desired successor is not interested to take over family business, succession becomes impossible.

Offspring usually makes their career decisions sometime between age 18 and 28 (Stavrou, 1998), (Birley, 1991), (Handler, 1989), (Longenecker and Schoen, 1991), (Ward, 1987). The age between 20 and 30 corresponds and the choice of occupation corresponds to development of personal identity. It is as well a stage of fast professional growth and creation of economical basis for independent life. In fact, in many cases people with family background prefer to gain experience outside family company. It is of paramount importance to understand what factors will encourage and discourage young adults to join or to return to family firm.

Literature on succession in family firm widely confirms intrinsic and extrinsic motives as a career motivation for successors. Transcendent motives are also mentioned (Stavrou et al. 2005), (Ventler et al. 2005), (Irving 2005), (Stavrou, 1998). Table 1 summarizes types of motivation that can be found in literature on succession. 


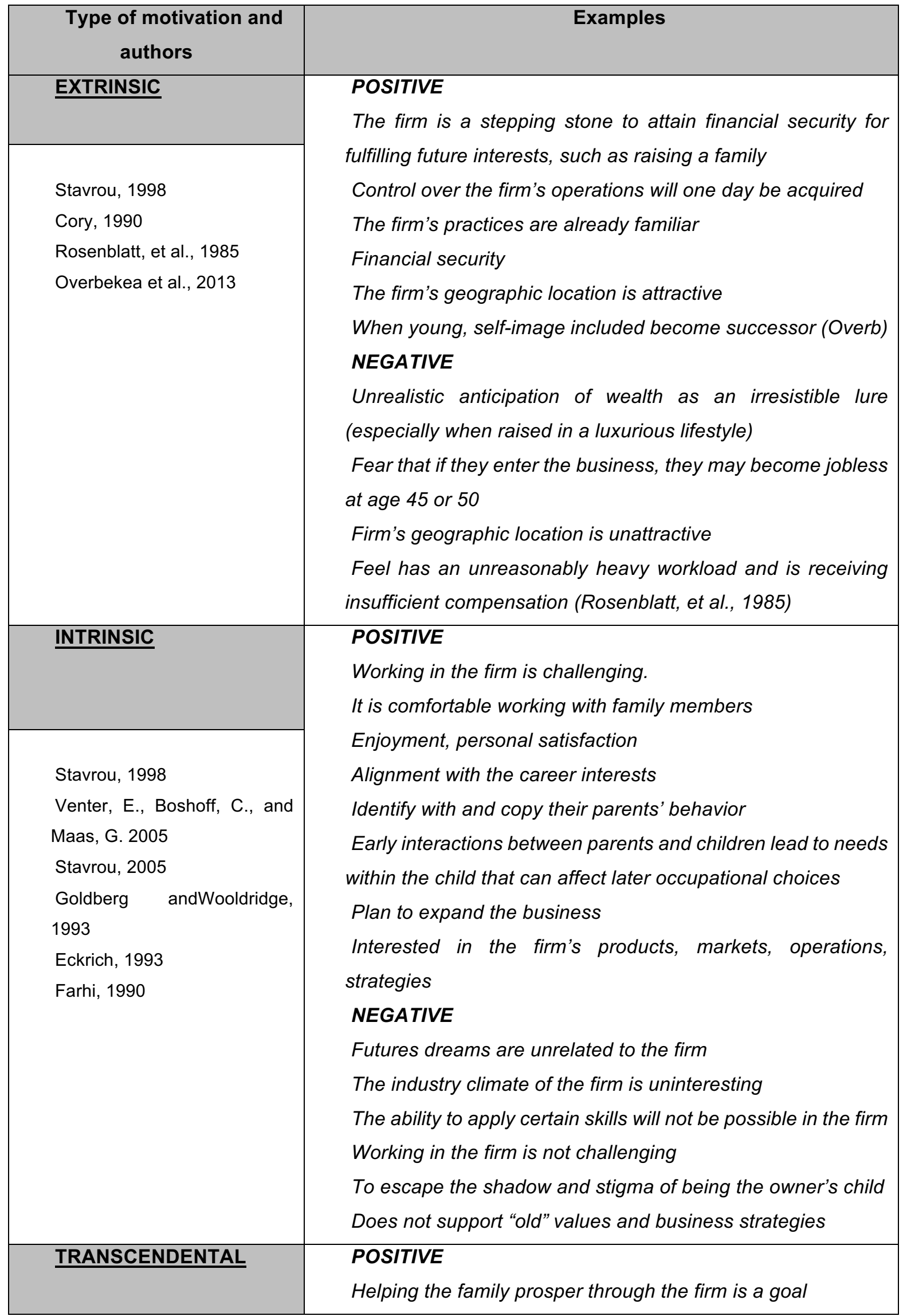


What makes a woman to choose to work in a family company instead of a looking for a position in the work market or creating her own company?: a literature review

\begin{tabular}{|l|l|}
\hline Stavrou, 1998 & NEGATIVE \\
& $\begin{array}{c}\text { The family business does not emphasize important family } \\
\text { values }\end{array}$ \\
\hline
\end{tabular}

Source: Own elaboration

Table 1. Motivation of successor. Humanistic theories framework.

Literature on Daughter succession also widely confirms basic motivational dichotomy. Intrinsic and extrinsic motives mentioned in these articles are similar to those-mentioned by articles on general succession. Table 2 summarizes types of motivation indirectly cited in literature on daughter succession.

Analyzing differences, we can note specific topics that are probably related to gendertopics that might give us a clue to some subtle gender differences that exist in motivation. For example, daughters would mention comfortable lifestyle and flexible environment to raise children, while articles that do not specify gender would not mention this. Further, among negative extrinsic reasons researchers cite birth order (which already appeared in this work) and the opinion of the spouse.

The section of intrinsic motivation for men and women is more elaborated compared to that of daughters in both: positive and negative factors. Some specific goals of professional interest are more often mentioned. It seems that on average daughters mention specific career goals less frequently.

In section of transcendent motivation the picture seems to be the opposite. Although this section is less elaborated in both cases, it seems that daughters thought more of general well being for family and family business and thus provide more examples of transcendent motives. This idea is also supported by the often-mentioned observation that daughters come to family business during hard times and moments of crisis - when either family or business needs support or when a supposed successor would reject the position or in case of accidental death (i.e. Dumas, 1998). It also is consistent with a stream of literature that links female leadership with transformational style leadership, which in turn is consistent with prosocial behavior (Grant, 2011).

In general for this section, it seems that; even though the concepts of intrinsic, extrinsic and transcendent motives are universal for both genders, the structure and sense that both genders put into each concept varies slightly. It seems that daughters have greater variety of extrinsic (or hygiene) reasons to be in family business. Flexibility of job design - is an 
addition to the factor of money and shares. It seems that for daughters sometimes is important to have shares without participation in management of the firm. Secondly, prosocial and transcendent motives are more appealing to daughters. These observations are somewhat consistent with traditional gender roles.

\begin{tabular}{|c|c|}
\hline $\begin{array}{c}\text { Type of } \\
\text { motivation and } \\
\text { authors }\end{array}$ & Examples \\
\hline EXTRINSIC & $\begin{array}{l}\text { POSITIVE } \\
\text { Facilitating family life } \\
\text { Farm's ability to sustain several families }\end{array}$ \\
\hline $\begin{array}{l}\text { Dumas, } 1995 \\
\text { Dumas, } 1998 \\
\text { Curimbaba, } 2002 \\
\text { Vera and Dean } 2005 \\
\text { Otten-Papas } 2013 \\
\text { Overbekea, et al. } \\
2013\end{array}$ & $\begin{array}{l}\text { Comfortable lifestyle; and a flexible environment for } \\
\text { raising children } \\
\text { Opportunity was "too good to pass up" and "the best thing } \\
\text { to come along," } \\
\text { Money, shares } \\
\text { Position nobody wanted } \\
\text { NEGATIVE } \\
\text { Spouse not interested } \\
\text { Birth order } \\
\text { IDEN: When young, self-image didn't include become } \\
\text { sUccessor }\end{array}$ \\
\hline & $\begin{array}{l}\text { IDEN: Affirmation of choice of profession } \\
\text { Roots in the business (farming) } \\
\text { INTJ: "a chance to prove myself," challenging chance to } \\
\text { shine, prove their abilities, and excel in a way that they } \\
\text { were unable to in outside employment. Changes - } \\
\text { opportunity to help; work excellence }\end{array}$ \\
\hline INTRINSIC & $\begin{array}{l}\text { POSITIVE } \\
\text { Interesting, challenging, and satisfying work }\end{array}$ \\
\hline $\begin{array}{l}\text { Dumas, } 1995 \\
\text { Dumas, } 1998 \\
\text { Curimbaba, } 2002 \\
\text { Vera and Dean, } 2005 \\
\text { Otten-Papas, } 2013 \\
\text { Overbekea, et al. } \\
2013\end{array}$ & $\begin{array}{l}\text { Variety of daily tasks } \\
\text { Job satisfy } \\
\text { Loves working for my family business - wonderful quality } \\
\text { of life }\end{array}$ \\
\hline
\end{tabular}


What makes a woman to choose to work in a family company instead of a looking for a position in the work market or creating her own company?: a literature review

\begin{tabular}{|l|l|}
\hline & $\begin{array}{l}\text { Lack of interest } \\
\text { Dislike of some aspect of farm lifestyle }\end{array}$ \\
& \\
\hline TRANSCEDENTAL & POSITIVE \\
\hline & "A family dream" \\
\hline Dumas, 1998 & "Giving back to the family" \\
Curimbaba, 2002 & Help family \\
Vera and Dean, 2005 & Making contribution (unique leadership opportunity) \\
Overbekea, et al. & NEGATIVE - \\
\hline
\end{tabular}

Source: Own elaboration

Table 2. Motivation of female successor - Humanistic theories framework

\subsection{Cognitive theories and succession}

To our knowledge, there is only one recent article that explicitly compares career intentions of young professionals with family business background using lenses of cognitive theories of motivation. Specifically, Zellweger et al. (2010) compares intentional founders, successors and employees on entrepreneurial self-efficacy, independence and innovation motives. According to the article, entrepreneurial selfefficacy and independence motive lead to preference of external employment over succession and entrepreneurship. Further, innovation intent leads to preference of founding experience over succession and external employment.

The limitation of this research consists in that it is a pioneering article. The number of variables studied is limited compared to the general amount of research dedicated to entrepreneurial intent and its antecedents. The article sheds some light on the topic of career intentions but still does not provide answers to why would a young professional would prefer family firm to other career options.

Literature, that concentrates only on successors in family firms neither provide answers. In general, successor pathways to leadership can be learned. No doubts that early initiation to business, small tasks in the firm and positive attitudes of parents to business favor development of healthy identity and the interest of the offspring in preservation of business within the family. 
Similar trends can be found in literature dedicated to family business daughters, with a difference that gender stereotypes may play a negative role when a daughter assesses her leadership potential in general and for family business specifically. Thus, parents who do not engage their daughters to work in family business early in life, do not foster their selfesteem in leadership and do not discuss future career opportunities with them - thus support indirect clues to daughters that they are not welcomed in the firm and that their opinion does not matter. It is not surprising that in adolescent age such daughters are excluding themselves from family business opting for external employment or entrepreneurship career.

Rivalry, as well, might play a deterring role in daughter's willingness to take business over. According to Expectancy-Value theory, negative expectations play a strong deterring role over intentions. Daughters anticipating a family relations instability and conflicts due to rivalry with brothers or with current business owner (father or mother), might as well simply exclude themselves from successor attempts.

Receiving unclear messages from parents may deter daughters from considering succession. Difficulty discerning family roles from business roles and mixing family (and personal) expectations with business expectations ("full control of business and produce grandchildren") may be perceived as a barrier by a daughter. Business values that do not reflect family values might undermine positive attitude toward family business and decrease its perceived value.

Table 3 resumes this part and presents particular examples taken from literature on family firm and female successors. It can be seen, from the point of view of cognitive theories, differences in social experiences might have a ripple effect in daughter motivation and result in self-exclusion. 
What makes a woman to choose to work in a family company instead of a looking for a position in the work market or creating her own company?: a literature review

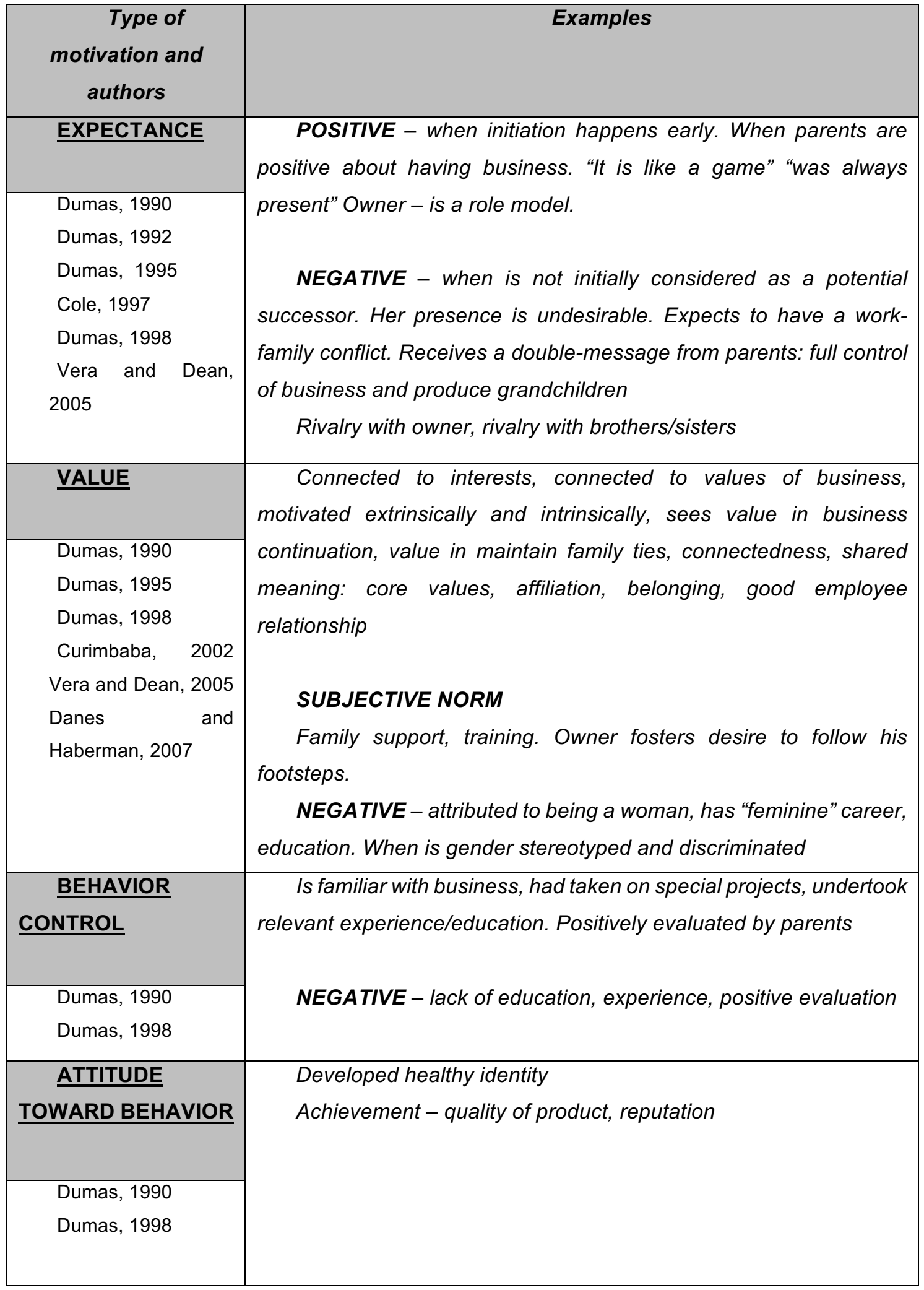

Source: Own elaboration

Table 3. Motivation of female successor - Cognitive theories framework 


\section{Conclusions}

Literature on successor motivation in family firms is scarce, given the important role succession plays and relative development of sister-areas: motivation of intentional entrepreneurs and employees. For studies of gender such this gap is even wider.

Given the rise of individualism and variety of careers available on the market, the lack of understanding of successor motivation and successor qualities leads to that family firms might be losing important human capital in face of daughters and their descendants. To address the gap a literature review was conducted.

Literature review reaped the following results.

- Although there are no studies that explicitly use any humanistic theory of motivation to study rationale of daughters to follow footsteps of their parents in family firms, research dedicated to other objectives can be used to shed some light on this topic.

By doing so, the basic motivational dichotomy Extrinsic-Intrinsic motivation is confirmed for both genders. However, a direct comparison suggests that male and female motivation is developed by slightly different trajectories. Specifically, extrinsic or material motives of daughters include flexible schedules, comfortable lifestyles and having shares of business. On the other hand, men's Intrinsic motivation includes slightly more specific career goals.

Finally, daughters seem to be more preoccupied with emotional component - and show greater variety on transcendent and prosocial motivation. This finding is consistent with the stream of literature on gender leadership styles, and possibly could have been more developed within literature on succession.

- In relation to cognitive theories, "ideal" successor's pathways to family business seem to be universal for both genders: an early initiation through conversations during family dinner and small summer projects and followed by a relevant education and some experience. However, literature suggests, that daughters are sometimes excluded (or exclude themselves) from potential successors; therefore, lacking this initiation phase.

In general, the role of family, early role models and experience are cornerstone for both genders. However, having father or mother involved in a business does not automatically provide next generation with desire to enter this business. Contrary to expected, young professional with family business background often opt for external employment or create their own companies. 
To date the potential of application of cognitive motivation theories to family firm field is untapped. As far as we know, only one paper explicitly compares different types career intentions for the youth with family business background. It can be inferred from other sources that the way men and women perceive their abilities, their chances to success and etc. differs as a function of their social experiences. Consequently, using cognitive theories might contribute to understanding the problem of female underrepresentation in family business.

Future research into the problem of gender imparity might gain from empirical studies both qualitative and quantitative - using both motivation theories frameworks. As such, interviews with female leaders in family firms might reveal greater emotional connection to family firms and greater extent of transcendent and prosocial motives than it is currently known. Such knowledge could have been used by academics and professional coaches, who develop business programs.

On the other hand, a quantitative study of young professionals using cognitive theories frameworks might reveal differences in entrepreneurial, employee and successor intentions as well as gender differences in corresponding career plans. More detailed information would provide a better theoretical and practical understanding of social experiences faced by family business daughters and sons. 


\section{REFERENCES}

Ajzen, I. (1991). The theory of planned behavior. Organizational behavior and human decision processes, 50(2), 179-211.

Bandura, A. (1977). Self-efficacy: toward a unifying theory of behavioral change. Psychological review, 84(2), 191.

Bernard, C. (2013, June 5). European Family Businesses and KPMG announce collaboration, in KPMG Family Business News, retrieved from: http://www.kpmgfamilybusiness.com/european-family-businesses-and-kpmg-announcecollaboration/

Birley, S. (1991). Succession in the family firm: The inheritor's view. In Family Business Sourcebook (pp. 126-134). Detroit: Omnigraphics.

Bussey, K., and Bandura, A. (1999). Social cognitive theory of gender development and differentiation. Psychological Review, 106, 676-713.

Chengyan, L. I., Lili, B. A. O., and Jiang, Q. (2013). Leadership styles of entrepreneurial women in eastern china: Characteristics and differences. Social Behavior \& Personality: An International Journal, 41(3), 421-431. doi:10.2224/sbp.2013.41.3.421

Cole, P. M. (1997). Women in family business. Family Business Review, 10(4), 353-371.

Colli, A., Perez, P. F., and Rose, M. B. (2003). National determinants of family firm development? family firms in britain, spain, and italy in the nineteenth and twentieth centuries. Enterprise and Society, 4(1), 28-64.

Cory, J. (1990). Preparing your successor: Family ownership. Hardware Age, 227(7), 74. Curimbaba, F. (2002). The dynamics of women's roles as family business managers. Family Business Review, 15(3), 239-252.

Deci, E.L. and Ryan R.M. (2000). Self-Determination theory and the facilitation of intrinsic motivation, social development, and well-being. American Psychologist, 55(1), $68-78$.

Dumas, C. (1989). Understanding of Father-Daughter and Father-Son dyads in FamilyOwned businesses. Family Business Review, 2(1), 31-46.

Dumas, C. (1998). Women's pathways to participation and leadership in the familyowned firm. Family Business Review, 11(3), 219-228.

Dumas, C. A. (1990). Preparing the new CEO: Managing the father-daughter succession process in family businesses. Family Business Review, 3(2), 169-181.

Dumas, C., Dupuis, J. P., Richer, F., and St-Cyr, L. (1995). Factors that influence the next generation's decision to take over the family farm. Family Business Review, 8(2), 99-120. 
Eagly, A. H., and Johnson, B. T. (1990). Gender and leadership style: A metaanalysis. Psychological Bulletin, 108(2), 233.

Eagly, A. H., Johannesen-Schmidt, M. C., and Van Engen, M. L. (2003). Transformational, transactional, and laissez-faire leadership styles: A meta-analysis comparing women and men. Psychological Bulletin, 129(4), 569-580.

Eckrich, C. (1993). Effects of family business membership and psychological separation on the career development of late adolescents. Unpublished doctoral dissertation, Purdue University.

Ely, R. J., Ibarra, H., and Kolb, D. M. (2011). Taking gender into account: Theory and design for women's leadership development programs. Academy of Management Learning \& Education, 10(3), 474-493.

European Family Business Report (2012, June). Family Business Statistics. Retrieved from: http://www.europeanfamilybusinesses.eu/uploads/Modules/Publications/familybusiness-statistics.pdf

Farhi, P. (1990, 9 July). Stepping into the family business: Responsibility often weighs heavily on heirs who must take over companies. The Washington Post, p. F1.

Fernández Pérez, P., and Hamilton, E. (2007). Gender and family firms: An interdisciplinary approach. Documents De Treball (Facultat d'Economia i Empresa.Espai De Recerca En Economia), 2007, E07/171.

Gillis-Donovan, J. and Moynihan-Bradt, C. (1990). The power of invisible women in the family business. Family Business Review, 3(2), 153-167.

Goldberg, S. and Wooldridge, B. (1993). Self-confidence and managerial autonomy: Successor char- acteristics critical to succession in family firms. Family Business Journal, 6(1), 62-69.

Grant, A. M., and Berry, J. W. (2011). The necessity of others is the mother of invention: Intrinsic and prosocial motivations, perspective taking, and creativity. Academy of Management Journal, 54(1), 73-96.

Grant, A. M. (2008). Does intrinsic motivation fuel the prosocial fire? Motivational synergy in predicting persistence, performance, and productivity. Journal of Applied Psychology, 93, 48-58.

Haberman, H. and Danes, S. M. (2007). Father-daughter and Father-son family business management transfer comparison: Family FIRO model application. Family Business Review, 20(2), 163-184.

Hamilton, E. (2006). Whose story is it anyway? narrative accounts of the role of women in founding and establishing family businesses. International Small Business Journal, 24(3), 253-271. 
Handler, W. C. (1989). Methodological issues and considerations in studying family businesses. Family business review, 2(3), 257-276.

Harter, S. (1978). Effectance motivation reconsidered. Toward a developmental model. Human development, 21(1), 34-64.

Herzberg, F., Mausner, B., and Snyderman, B. B. (2011). The motivation to work (Vol. 1). Transaction Publishers.

Hollander, B. S., and Bukowitz, W. R. (1990). Women, family culture, and family business. Family Business Review, 3(2), 139-151.

Instituto de la Empresa Familiar Report (2009). Retrieved from: http://www.iefamiliar.com/web/es/IEF_English.pdf

Vadnjal, J., Zupan, B., (2009) The Role of Women in Family Businesses. Economic Business Review, 11 (2).

Longenecker, J. G., and Schoen, J.E (1991). Management Succession in the Family Business, in Family Business Sourcebook. Ed. C. A. Aronoff, and J. L. Ward. Detroit, MI: Omnigraphics, Inc., 150-156.

López, J. A. P. (1991). Teoría de la acción humana en las organizaciones: la acción personal. Ediciones Rialp: Barcelona.

López, J. A. P. (1996). Fundamentos de la dirección de empresas. Ediciones Rialp: Barcelona.

Maleki, N., Askari, A., and Ghanbari, M. A. (2011). Designing an effective female leadership model in governmental organizations. Journal of Knowledge Management, Economics \& Information Technology, 1(6), 493-514.

Marshack, K. J. (1994). Copreneurs and dual-career couples: Are they different? Entrepreneurship Theory and Practice, 19, 49-49.

Maslow, A. H., Frager, R., and Cox, R. (1970). Motivation and personality in J. Fadiman, \& C. McReynolds (Eds.). New York: Harper \& Row.

McConaughy, D. (1994). Founding-family-controlled corporations: An agency-theoretic analysis of corporate ownership and its impact upon performance, operating efficiency and capital structure. Doctoral dissertation, University of Cinncinati.

McConaughy, Daniel L., Michael C. Walker, Glenn Henderson Jr., and Chandra S. Mishra (1998). Founding Family-Controlled Firms: Efficiency and Value. Review of Financial Economics, 7(1), 1-19.

McGregor, D. (1960). The human side of enterprise. Harper Collins: New York.

Otten-Pappas, D. (2013). The female perspective on family business successor commitment. Journal of Family Business Management, 3(1), 8-23. 
Overbeke, K. K., Bilimoria, D., and Perelli, S. (2013). The dearth of daughter successors in family businesses: Gendered norms, blindness to possibility, and invisibility. Journal of Family Business Strategy, 4(3), 201-212.

Pascual Garcia, C. (2012). Empresa Familiar: Mujer y Sucesión. Universidad de Cordoba: Cordoba.

Powell, G. N. (2010). Women and men in management. Sage: London.

Poza, E. J. and Messer, T. (2001). Spousal leadership and continuity in the family firm. Family Business Review, 14(1), 25-36.

Rosenblatt, P.C., de Mik, L., Anderson, R.M., and Johnson, P.A. (1985). The family in business: understanding and dealing with the challenges entrepreneurial families face. San Francisco, CA: Jossey-Bass.

Salganicoff, M. (1990). Women in family businesses: Challenges and opportunities. Family Business Review, 3(2), 125-137.

Sharma, P. (2004). An overview of the field of family business studies: Current status and directions for the future. Family Business Review. Retrieved from http://onlinelibrary.wiley.com/doi/10.1111/j.1741-6248.2004.00001.x/full

Sharma, P., and Irving, P. G. (2005). Four bases of family business successor commitment: Antecedents and consequences. Entrepreneurship Theory and Practice, 29(1), 13-33.

Sieger, P., Nason, R., Sharma, P. and Zellweger, T. (2012). STEP Global Booklet (Spanish version) / Folleto mundial de STEP (p. paper 8).

Simon, H. (2009). Hidden champions of the twenty-first century: The success strategies of unknown world market leaders. Springer Science \& Business Media: London.

Stavrou, E. T. (1998). A four factor model: A guide to planning next generation involvement in the family firm. Family Business Review, 11(2), 135-142.

Stavrou, E. T., Kleanthous, T. and Anastasiou, T. (2005). Leadership personality and firm culture during hereditary transitions in family firms: Model development and empirical investigation. Journal of Small Business Management, 43(2), 187-206.

Stavrou, E. T., Kleanthous, T. and Anastasiou, T. (2005). Leadership personality and firm culture during hereditary transitions in family firms: Model development and empirical investigation. Journal of Small Business Management, 43(2), 187-206.

Vera, C. F. and Dean, M. A. (2005). An examination of the challenges daughters face in family business succession. Family Business Review, 18(4), 321-345.

Wang, C. (2010). Daughter exclusion in family business succession: a review of the literature. Journal of family and economic issues, 31(4), 475-484. 
Ward, J.L. (1987), Keeping the Family Business Healthy, San Francisco, CA: JosseyBass. Ward, J.L. (1991), Creating Effective Boards for Private Enterprises, San Francisco, CA: Jossey-Bass. Ward,J.L. and Handy, J.L. (1988), 'A survey of board practices', Family Business Review, 1(3), 289-308.

Wigfield, A., and Eccles, J. S. (2000). Expectancy-value theory of achievement motivation. Contemporary educational psychology, 25(1), 68-81.

Zellweger, T. M., Nason, R. S., and Nordqvist, M. (2012). From longevity of firms to transgenerational entrepreneurship of families introducing family entrepreneurial orientation. Family Business Review, 25(2), 136-155.

Zellweger, T., Sieger, P., and Halter, F. (2011). Should I stay or should I go? Career choice intentions of students with family business background. Journal of Business Venturing, 26(5), 521-536. 